\title{
الاستحسان الأصولي والاجتهاد الفقهي المعاصر
}

\section{محمد الحاج سالم*}

مقدمة

جاءت الرسالة الخاتمة لإرساء جملة من القيم والتعاليم اقتضت حكمة الله تعالى أن تكون محل تكليف المكلفين لجلب المنافع لهم ودرء المفاسد عنهم في الدنيا والآخرة. بحيث لا يتسنى لهم تحصيل تلك المصالح إلا ته من طريقها. كما اقتضت إرادته تعالى ألا تكون حياقم على وتيرة معيشية واحدة من الابتلاء، بل تكتنفها حالات من السعة واليسر أحيانا، وتطرأ عليها حالات من الضيق والعسر أحيانا أخرى. والشارع العليم قد أحاط علمُه بكل ذلك فجعل شرعه شاملا لجميع تلك الحالات. واقتضى عدلُه ورحتُه بخلقه ألا تُناط بها جميعا الأحكام نفسها. فمع تطابق الأفعال الصادرة عن المكلفين في الفرع الفقهي الواحد، فإن آحادها قد تلتحق بحكم شرعي معلوم، وقد تخالفه إلى حكم آخر، بحسب ظرف المكلف وعوارض فعله.

وقد تعارف الأصوليون والفقهاء على إطلاق مصطلح "الأصل" على الأولى، باعتبار أن أفعال المكلفين متساوقة مع أحكامها أصالة، وإطلاق مصطلح "خلاف الأصل" على الثانية، باعتبار أن المكلف قد ألمت به بعض العوارض اقتضت إخراج فعله من مجال القاعدة العامة -التي هي الأصل- إلى خلافها على سبيل الاستثناء في الحكم.

والأمر إلى هذا الحد لا إشكال فيه من الناحية الأصولية النظرية، لأن إلحاق الفروع الفقهية بالأصل أو بخلاف الأصل، بل وتقسيم الأدلة والمفاهيم الأصولية نفسها إلى "أصل" و"خلاف أصل"، هو مجرد تقسيم منهجي، غايته تحديد الدائرة الأصولية التي يندرج ضمنها ذلك الفرع الفقهي، ليتيسّر للفقيه مدارسة المسألة العملية والنظر فيها في إطارها الأصولي الصحيح خلال مرحلة الاستدلال القاصدة إلى إدراك الحكم الشرعي المناسب، وهو الثمرة الفقهية النهائية التي ما وُضعت القواعد والضوابط الأصولية إلا من أجل تحقيقها. 
ولكن الإشكال نتج عن سوء تقدير بعض الفقهاء في إلحاق كثير من الفروع الفقهية بالدائرة الثانية وهي دائرة خلاف الأصل- خلال مدارساتم لها والتماسهم لمسالكها الاستدلالية المناسبة. مما نتج عنه تضخيم دائرة "خلاف الأصل" على حساب دائرة "الأصل" في التشريع. وهذا العمل -فضلا عما فيه من خرق للضوابط الأصولية وبجانبة للمسالك الاستدلالية النظرية- فإنه قد أثر سلبا في الثمرة الفقهية نفسها، وذلك في كثير من الفروع الفقهية والقضايا الواقعية قديما وحديثا.

وتتجلى هذه الحقيقة واضحة للعيان خاصة فيما يتعلق بالفروع الفقهية التي يستلون عليها بدليل الاستحسان الأصولي، نظرا لكونه يمثل أجلى مسلك من مسالك الاستثناء من القواعد في التشريع أو من عموم القياس الذي هو الأصل المخالف.

وهذه الدراسة المتواضعة مع إقرارها بأهمية دليل الاستحسان الأصولي في الاعتماد عليه والاستدلال به خلال نظر الفقهاء المعاصرين في كثير من قضايا هذا العصر الشائكة، الفردية منها والجماعية خاصة، فإِها تأخذ عليهم مجاراتم المسلّمة للمسالك الاستدلالية نفسها التي انتهجها القدامى، والأخذ بها أو القياس عليها، دون تمحيص أو مراجعة لما كان للظرف الزماني وتحديات تلك العصور من شديد أثر فيه. مما نتج عنه مدارسة كثير من قضايا هذا العصر من خلال المنظور الأصولي الموروث نفسه، 1 بما شابهُ من زلاّت لا تناسب منطق الضبط الأصولي منهجيا، ولا تتناسب مع سماحة الشريعة الإسلامية ومقاصدها الغراء واقعيا.

\section{معالم دليل الاستحسان في النشاط الفقهي المعاصر}

1. أهمية دليل الاستحسان في الفقه المعاصر: تكاد بتمع كلمة الفقهاء المعاصرين على أهمية دليل الاستحسان في تنشيط حركة الاجتهاد الفقهي المعاصر، وكونه أصلا شرعيا لا محيد عنه في معالجة قضايا

تلك المسالك الاستدلالية مع أها موروثة من القديم عن غالب الفقهاء والأصوليين، فإن ذلك لم يمنع بعضهم من نقدها والاجتهاد في

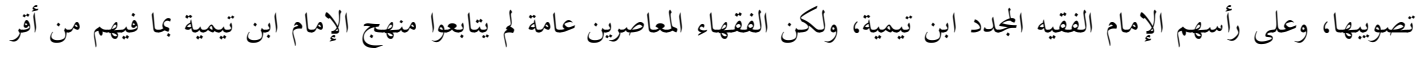

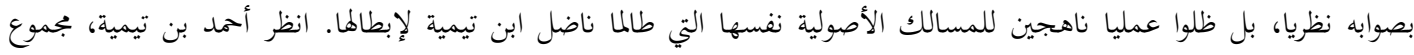

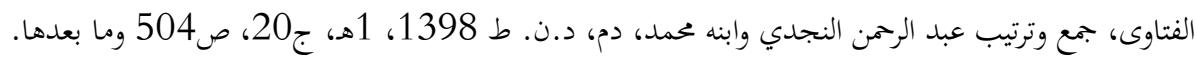


عصرنا الذي تعقدت فيه مطالب الحياة وتعددت وجوه الكسب والاننفاع بأنماط عملية من الوقائع الحادثة والمستجدات التي لا نظير لها في موروث التشريع الإسلامي. وهي أحوج لهذا الدليل ولغيره من الأدلة الأصولية المندرجة في دائرة خلاف الأصل في التشريع، من أي حقبة تاريخية مرت، وذلك لسبين:

أولما: أن تعثّر النشاط التشريعي طوال مرحلة الجمود والتقليد الفقهي قد خلّفت هوة بين مستوى حركة الاجتهاد البطيئة، وبين رُب النوازل ومستحدثات الوقائع المتسارعة. وتلك الثغرة لا تفي بملئها أدلة الأصل، بل الأجدر بها أدلة خلافه، وفي مقدمتها دليل الاستحسان.

وثانيهما: أن غُربة سلوك المسلمين عن تعاليم الشريعة بفعل جهلهم لمبادئها أو تنكرهم لها، تتطلب آمادا من مراحل الإصلاح التدريجي والمعالجات الظرفية، على أمل الوصول بواقع المجتمعات الإسلامية إلى وضع الأصل، وإخراجها من وضع الاستثناء. وفي انتظار ذلك فإن الحكمة تقتضي استفراغ الوسع في إعمال أدلة خلاف الأصل، وعلى رأسها دليل الاستحسان الذي يمثّل أجلى شاهد من شواهد المرونة والواقعية في التشريع الإسلامي. وفي تقرير ذلك يقول الفقيه القانوني الشيخ مصطفى الزرقاء: "إن ميزان قواعد العدل والإنصاف عند الفقيه المسلم المجتهد هو المقاصد العامة للشريعة. وإن أهم المسالك الموصلة إلى الأحكام البصيرة والحلول المستنيرة هو طريقا الاستحسان والاستصلاح، ثم رعاية أعراف الناس التي تعارفوها في بيئتهم وحياتم الاجتماعية والاقتصادية مما لا يتعارض مع نصوص الشريعة ومقاصدها العامة". 2

فهذا الأصل التشريعي رغم انخصاره وضيق أفقه مقارنة ببعض أدلة الأصل، باعتباره مرتبطا بوضع الاستثناء والأصلُ خلافُه، فهو مع ذلك يعد من أهم الأدلة الشرعية التي يجتاج إليها نشاط التشريع في عصرنا الحاضر. لأن أحقاب الجمود الفكري التي توالت على المسلمين، وما تبعها من حدوث فراغ تشريعي هائل قد باعدت بين سيرة المكلفين بالخطاب الشرعي وبين مقاصد دينهم. ومسعى الفقهاء المجددين بتحاه تقويم هذا الوضع السقيم، لا يكون بتجاهله ومحاولة القفز على تلك الموة قصد تخطيها في لمح البصر، بل الحكمة تقتضي أن يُتوخى في تصحيح ذلك الوضع مسالك التدرج. والجنوح إلى أحكام الاستثناء، إلى حين

الزرقا، مصطفى أمد، الفقه الإسلامي ومدارسه، دمشق، دار العلم، وبيروت: الدار الشامية، ط 1، 1416هـ/1995م، ص40، 
التمكن من جبر تلك الثلمة وتعبئة فراغها التشريعي، ثم العودة من جديد إلى الأحكام الكلية عند التحقق من استرجاع وضع الأصل. أما والمجتمعات الإسلامية اليوم لا تزال تعيش وضع الغربة عن مطالب الدين ومقاصده الكلية، فما من خيار لها غير سلوك فه التدرج.

ويرى الشيخ عبد المجيد النجار أن خيار التدرج التشريعي قد اقتضى في هذا العصر اتباع فجي "التأجيل" و"الاستثناء"، وعبّر عن رؤيته المنهجية هذه بالقول: "إن المقصود بالتأجيل هو العدول عن تطبيق الحكم الشرعي في ظرف معين، وإسقاط العمل به في ذلك الظرف حتى يهين ظرف آخر مناسب، يعاد فيه ذلك الحكم إلى التطبيق، والمقصود بالاستثناء وقف تطبيق الحكم الشرعي في حق عينة من عينات الأفراد أو الحالات، في حين يطبق على سائر العينات الأخرى المشابهة لها". 3

وفي بيان الحكمة من سلوك فه التدرج في تشريع الأحكام، يقرالشيخ النجار أن "المبرر الأساسي للتأجيل والاستناء هو وجود موانع فيما يراد أن يطبق عليه الحكم، بتعل تطبيق الحكم عليه لا يؤدي مقصود الشارع من وضعه، بل قد يؤدي ذلك التطبيق إلى ما يناقض المصلحة المقصودة". 4 ولكسب الدعم الشرعي التاريخي يلجأ الشيخ النجار إلى السيرة العمرية في الاجتهاد، فيورد النماذج الثلاثة المشهورة في تطبيق الاستحسان، المتمثلة في "وقف تنفيذ حد السرقة عام المجاعة"، و"تعطيل حصة المؤلفة قلوكم بعد انتشار الإسلام"، و"منع توزيع أرض العراق على الجنود الفاتحين".

ومن هنا يتبين مدى تعويل الشيخ النجار على أصل الاستحسان الذي عبر عنه بتعبيرات أقرب للغة أهل العصر هي "التدرج" و"التأجيل" و "الاستثناء" في معالجة واقع المسلمين المعاصر، وتدارك ما فات من مراحل عطالة النشاط التشريعي وقعوده عن الفعل، والاجتهاد في وصل سلوك المجتمعات الإسلامية الحالية بأحكام الشريعة ومقاصدها.

النجار، عبد الجيد عمر، فقه التدين فهما وتنزيا، كتاب الأمة، مؤسسة الخليج للنشر والطباعة، ط 13، جمادى الأولى، 1410هـ/ 
وليس في هذا السلوك الاجتهادي بِدْعُ من سُنة التشريع "فقد كانت هذه المرحلية المتدرجة في تنزيل أحكام الدين سنة نبوية، في التبشير بالإسلام... وعلى مدى ثلاثة وعشرين عاما خلصت الحياة بالتدرج من الجاهلية إلى الرشد... وإذا كان هذا التدرج في إنجاز الأحكام، رافق نزول الدين ابتداء لتحويل الجاهلية الجهاء إلى اهتداء مبين، فإن فيه تعليما للمسلمين ليقتبسوا منه فقها في الإنجاز، كلما وجدوا أنفسهم في وضع فيه شبه وإن يكن قريبا من ذلك الوضع الذي نزل فيه الدين". 5 ومن تََّ يتبين أن خيار المعالجة المتأنية لواقع المسلمين الاجتماعي الناهج للطرق المذكورة، ليس مسنودا فقط بدليل الاستحسان الأصولي، من الناحية التشريعية. بل هو مسنود أيضا بسيرة الرسول صلى الله عليه وسلم وسنته العملية الأقوى في دلالتها من الاستحسان نفسه. والتي تمثل شاهدا محكما على مصداقية هذا النهج، طالما أن اتباعه في سيرته والاقتداء به في طرق معالجته لقضايا الواقع وشؤون المجتمع واجب لا خيار فيه، وإلا لما كان لسيرته أي دلالة تشريعية.

وادعاء أن ذلك كان في مرحلة التلقّي حيث كان المجتمع الإسلامي في طور بنائه، الأول قبل أن يكتمل ذلك البناء، حيث كانت الآيات تتنزل وفق سنة التدرج، والنسخ في القرآن يعمل عمله. أما بعد انقضاء تلك الفترة بانقطاع الوحي، فقد اكتمل الدين واستقرت مبادئ الإسلام، ومن شاء اتباع فج الإسلام فعليه الأخذ به مكتملا لا منتقصا ولا متدرجا.... وغيرها من الدعاوى الهادفة إلى منع سلوك التدرج في تنزيل أحكام الإسلام، هي دعاوى واهنة لا أساس لها من الحق. لأن خيار التدرج سنة ثابتة يلزم الجنوح إليها كلما اقتى واقع المسلمين إعمالها إلى أن يرث الله الأرض ومن عليها. 6

ولا يعني ذلك البتة أن دليل الاستحسان وقْفُ على مراحل التدهور والانحطاط في واقع المسلمين، أو غيرها من الأحوال الاستنائية الظرفية. بل هو في جانب منه ملازم لسلوك المكلفين على سبيل الدوام

$$
\text { } 5
$$

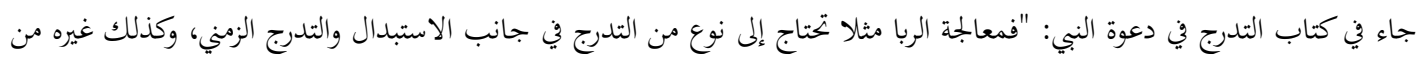

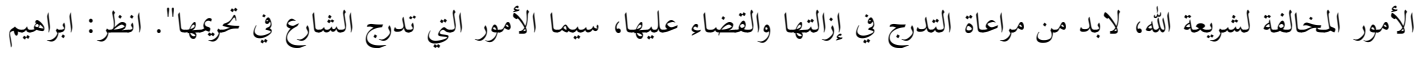

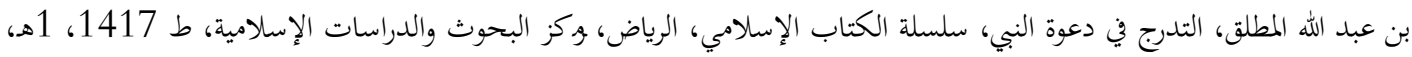


والاستمرار، فيما اصطُح عليه أصوليا باسم استحسان القياس الخفي، فالوقائع المندرجة فيه لا ترتن بأوضاع الطوارئ في علاقتها بواقع المكلفين، بل هي طارئة بالنظر إلى دليل القياس الأصولي المعدول عنه فيها إلى موضع المعنى الخفي. وكذا بعض الوقائع المندرجة في قياس الاستثناء من القواعد، فالمعهود فيها هو الاستثناء وليس القاعدة، لأن استثناءها من قواعدها على سبيل التأبيد كما في فروع السلم والجعالة والاستصناع والجزاف وغيرها.

بخلاف التكاليف الظرفية الملغاة أصالةً إذا انتفت منها مصلحتها في ذلك الظرف الطارئ، فإن طروها عارض على واقع المكلفين، كما في النماذج الفقهية العمرية المذكورة. وهذا الجانب هو المقصود بالإصلاح الظريف لأن الأصل في أفعال المكلفين خضوعها للأصول وقواعد التشريع العامة. وفي أوضاع الطوارئ تنتفي دواعي الأصل إلى حين تحقق أسبابه في الواقع.

وهو وضع واقع المسلمين المعاصر في بعض جوانبه، لأنه يمثل مرحلة انطلاق قاصدة إلى استئناف الحياة الإسلامية بعد توقفها خلال مرحلة الجمود التشريعي السابقة. فهي منعرج من مرحلة إلى أخرى تقتضي آليات في تقرير الأحكام وتنزيلها مخالفة لمعهود أطوار فضة التشريع وسلطانه في الواقع. 2. إرجاع فقهاء العصر فروع الاستحسان إلى دليل الاستصلاح: الاتحاه الغالب من فقهاء هذا العصر المؤمنين بشرعية هذا المسلك التشريعي أنفسهم، مع إقرارهم بشرعيته ولزوم الركون إليه نظريا، فإفم يعمدون عمليا، إلى إرجاع الفروع الفقهية الطائة على سبيل الاستحسان إلى دليل المصلحة المرسلة. فطالما أن مصلحة الجماعة المسلمة تقتضي ذلك فلا مانع عندهم من اتباعه في كل جزئية تتحقق فيها مصلحة المكلف. ولا داعي تبعا لذلك للبحث عن دليل تشريعي آخر لتأصيل مسالك الإصلاح الإجتماعي في الظروف الطارئة. خاصة وأن دليل الاستصلاح بما يمتاز به من مرونة، هو أجدى لذلك، لإمكان تعلّقه بكل فرع دون تقيّد بأنواع الأفعال وأجناسها من ناحية، وانفكاكه عن كثافة الضوابط الفنية التي تبطّئ نشاط الفقيه وتعقّد سعيه مع وضوح مناط المصلحة. خلافا لدليل الاستحسان فإنه لا يتصف بتلك المرونة، ويقتضي إعماله ضرورة استحضار شواهد إثبات اندراج الواقعة المراد البت فيها ضمنه. وهذا أمر نسبي 
تتنتف فيه أنظار المجتهدين بحسب اختلافهم في مسالك الاستحسان وما يدخل فيه وما لا يدخل مما يسمونه بأدلة الاستحسان.

وهذا المبرر مع وجاهته بالنظر إلى مقصد تسهيل عمل الفقهاء المجتهدين في انتهاج أيسر السبل التشريعية المساعدة على الإسراع في إنجاز أهداف الإصلاح الاجتماعي، فإنه لا يستقيم ذريعة -من الناحية الأصولية- لإخراج تلك القضايا من دائرة الاستحسان وإلحاقها بدائرة المصلحة المرسلة. لأن دليل الاستصلاح لا يدخل فيه غير المرسل من الوقائع مما لا دليل على تشريعه ولا نظير له على التفصيل، ولا قاعدة شرعية يندرج فيها. خلافا لهذا الضرب من الوقائع فلا تنفك عن واحد من تلك الشروط لتلتحق بدائرة الإرسال. ومن ثم فإن التزام ضوابط القواعد الأصولية تقضي إلحاقها بدليل الاستحسان.

فضلا عن أن سلوك فج الاستحسان يجعل كلا من الفقهاء المجتهدين المكلفين في المجتمع الإسلامي عامة مستحضرين لحقيقة في غاية الأهمية، هي أن ذلك العدول ظرفي دفع إليه الواقع الطارئ في انتظار تحقق شروط تنزيل أحكام الأصول والقواعد العامة فتُستعاد مرة أخرى، وأنه ليس هو الحكم الشرعي المأمول المتعلق بالواقع الأمثل، حتى يكون المكلفون على بينة من أمرهم فيكون لهم ذلك حافزا لتجاوز الطور الطارئ واستعادة أحكام أصول الشريعة وقواعدها. خلافا لسند المصلحة المرسلة فلا تتحقق فيه تلك الحكمة ولا ذلك الحافز. بل قد يؤول إلى اعتقاد العامة أن ذلك الحكم المقرر هو الأصل الثابت على الدوام، طالما هو قائم على دليل المصلحة. وإذا ما سعى القائمون على أمور المسلمين إلى بتحاوز ذلك الوضع الطارئ وتحقت شروط العدول عن الاستحسان نفسه إلى القواعد ثارت شبهة ترك المصلحة بترك حكمها الأول من قِبل العامة، والتشكيك في مشروعية العدول عن الاستحسان إلى القاعدة، بشبهة أنه لم يقع العدول عن القاعدة ابتداء حتى يُعدَل عن المعدول ويُستعاد الأصل. لأن تفكير العامة لا يقبل ذريعة العدول عن المصلحة إلى المصلحة في حال تغيّر الحكم، فالمصلحة في نظرهم مناطها واحد وثابت بثبات أحكام الدين. وهذه الشبهة يمكن اتقاؤها في حال التصريح بالحكم القائم على دليل الاستحسان. مع ضرورة تنوير العامة لحقائق الأمور وحثهم على السعي إلى استعادة أوضاع الأصل، فيتقبلون أحكام الطوارئ المستثناة على بصيرة، وتشرئب 
أعناقهم إلى تحاوز أوضاع الاستثناء فلا يمانعون من العدول عنها إلى غيرها عند تحقق شروط ذلك العدول بالحق والقسطاس.

3. تجربة المصارف الإسلامية في ضوء الاستحسان: ومن أظهر الشواهد التي يجدر استحضارها في

هذا المقام مثال إنشاء المصارف الإسلامية خلال العقود الثلاثة الأخيرة. فبعد أن كان نشاط المصارف ومعاملاتما المالية قائما على أساس الفوائد الربوية ولا وجود البتة لأنماط المعاملات المصرفية الإسلامية، ابتهت همة بعض أهل العزائم إلى محاولة إنشاء المؤسسات المصرفية القائمة على المبادئ الإسلامية، في ظروف صعبة وبغير سابق بحربة عملية ولا تأصيل نظري كاف للتوجيه والإنجاز.7 وكان لابد من أن تمر تلك التجارب الوليدة خلال مراحلها الأولى ببعض الأخطاء والنواقص كأي جهد بشري جماعي في بداياته. ومع ما حققته تلك التجارب من نجاح ه وتمنها من البقاء والاستمرار إلى جانب المؤسسات المصرفية التجارية العملاقة، 9 وفي وضع منافستها الشديدة غير النزيهة، 10 ومحاربة القوى المعادية العتيدة لها. فإن بعض الفئات من داخل الدائرة الإسلامية نفسها لم ترض عن نشاط تلك المصارف الوليدة لأهما لم تر من مسيرتا غير تلك النواقص، فحملت عليها بشدة واصمة ذلك الجها الجبار بشتى النعوت، بدعوى منع استغلال الانتساب للشريعة بغير وجه حق. معتبرة أن تلك المؤسسات التي تدعي الصفة الإسلامية لا تفارق غيرها من المصارف التجارية في غير الاسم. وأنه لا يجوز تسميتها باسم الإسلام ولا اعتبار معاملاتما المالية متسمة بسمة

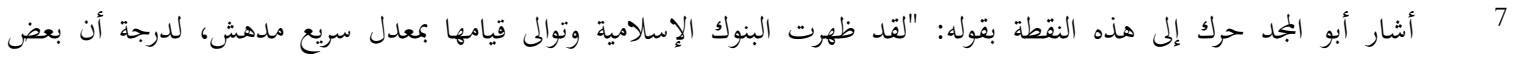

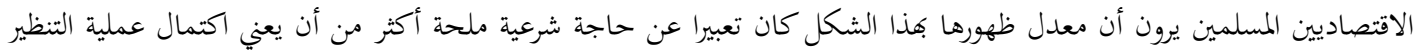

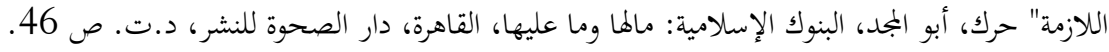

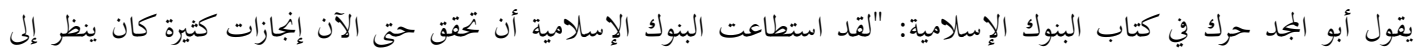

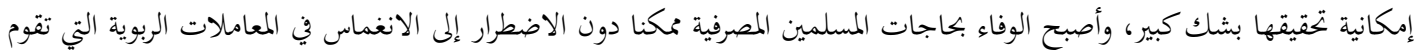

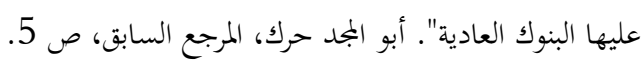

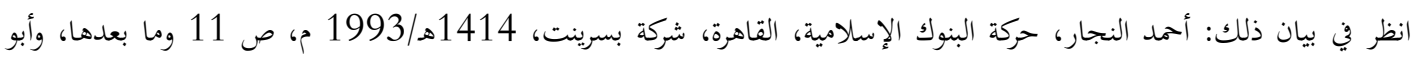

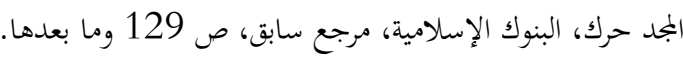

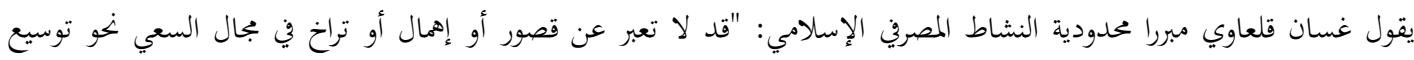

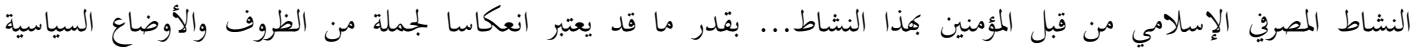

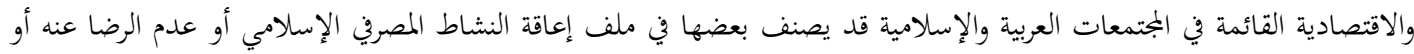

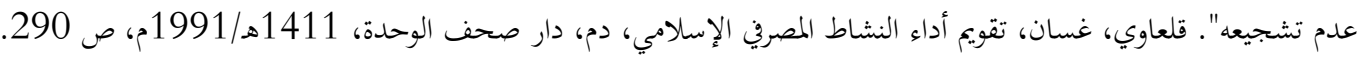




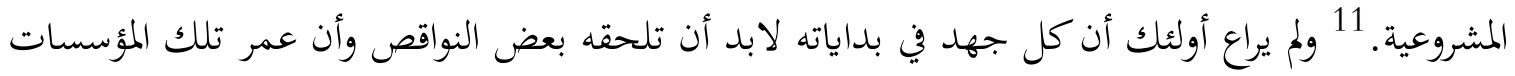
لا يفي بتخليصها تماما من شائبة الحرام، وأن ذلك يحتاج إلى وقت تنضج فيه بحارب القائمين على ذلك العمل لتسديد خطاه، ويطمئن فيه المتعاملون إلى سلامة فجه لحفظ أموالهم ونمائها في ظله، وتتكثف فيه اجتهادات الفقهاء لإظهار وجه الحق فتكون معينا على التسديد وحسن التوجيه وتدفعها إلى الأمام دون

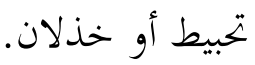

ولو كان أولئك الناقمون على تحربة المصارف الإسلامية من داخل الدائرة الإسلامية عارفين بحقيقة دليل الاستحسان الأصولي وأبعاده الفقهية، لما وقفوا ذلك الموقف المعيق ولا التخوا تلك الأسباب ذريعة لهجومهم، لأن سنة التدرج في تنزيل أحكام الشريعة تسمح بالتغاضي عن خوارق بعض أحكام الشريعة في مثل تلك الظروف إذا كان ذلك التجاوز متعلقا ببعض الأحكام ويتحقق بفضله أحكاماً أخرى بعد أن كانت عديمة تماما، لأن ما لا يدرك كله لا يترك جله بل يُستجَلب ولو قليله ليكون بداية لتحقيق الكل. 12 وبناء على ذلك لو ابتهت همة بعض أولي الأمر من القائمين على شؤون المسلمين إلى مسعى أسلمة بعض المصارف أو غيرها من المؤسسات المالية، ولم يكن ذلك ممكنا دفعة واحدة بل لابد من سلوك فج التدرج في تحقيق تلك الغاية، فإن تعاليم الشريعة تقضي بوجوب مباركة ذلك المسعى وممد أصحابه مع أنه قائم على أسس غير شرعية طالما أنه ساع إلى الانتقال من وجوه الكسب الحرام جاد في التماس وجوه الكسب الحلال، ولا يمكن أن يتحقق ذلك إلا خلال أمد زمني قد يطول، كما هي طبيعة العمل المؤسسي المحوط بأنماط المعاملات اللامشروعة في مجتمعات أُشربت طرائق السلوك العلماني الغربي بداية من قطاعاتما

يقول الشيخ محمد الغزالي في رده على دعاوى هؤلاء: "إني لأعجب من بعض المسلمين يسكتون عن بنوك ربوية مائة في المائة، ويثيرون

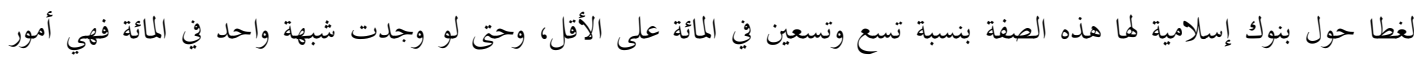

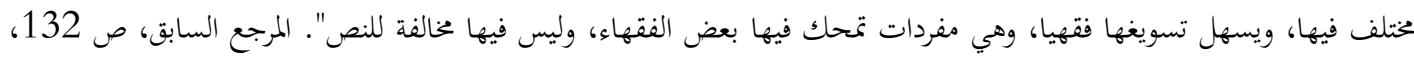

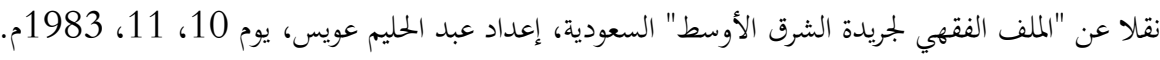

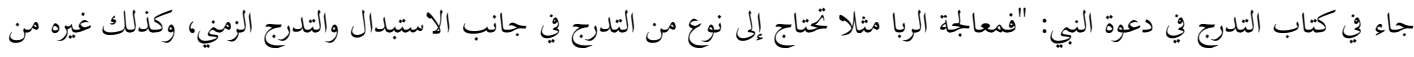

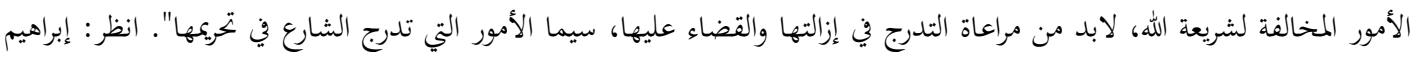

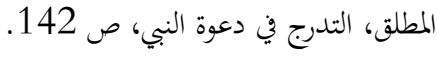


التعليمية والمالية وانتهاء بمؤسساها السياسية التي بتذرت في منطلقاها وتشابكت في علاقاها وارتباطاتا بشبكة المؤسسات العالمية العملاقة التابعة للأمم الرأسمالية الغالبة ونشأت في ظلها.

وفي تأكيد ذلك يقول الفقيه القانوني الأستاذ توفيق الشاوي: "لما كان التنظيم المصريف في معظم الدول الإسلامية حسب تركيبه الحالي يعتبر نتاج تاريخ طويل فرضته أحداث لا يد للمسلمين فيها، لذلك قد يكون من العسير إحداث تغيير جذري في هيكل الجهاز المصرفي وفي الدور الذي يضطلع به كل قسم من أقسامه في فترة قصيرة. فتغيير تركيب البنوك وإعطاؤها المهام الجديدة التي تتمشى مع حاجات الاقتصاد الإسلامي يستحسن أن يكون تدريجيا لكي تتمكن البنوك والمتعاملون معها من الانتقال من المعاملات والأساليب غير الشرعية إلى المعاملات والأساليب الشرعية في يسر". 13

4. الاستحسان وإصلاح التعليم: ومن أظهر الشواهد التي يجدر استحضارها في هذا المقام أيضا، مثال إصلاح التعليم في بعض المجتمعات الإسلامية والعمل على تغيير مناهجه ومضامينه بما يتلاءم مع مبادئ الشريعة الإسلامية وتعاليمها، " ففي المدارس والكليات يُلقّّن ويكرّس الاغتراب والابتعاد عن الإسلام وتراثه ونمطه في الحياة، بحيث صار نظام التعليم الحالي هو المختبر الذي تصاغ فيه تركيبة الشباب المسلم ويجري تغذية وعيهم على أسس غربية باطلة". 14

ومن ثم فإن واجب إصلاح التعليم في المجتمعات الإسلامية هو من آكد الواجبات التي يتعين على ولاة أمور المسلمين التوجه إليها بالعناية وتوجيه الطاقات الذهنية والمالية للوقوف على حلولها. وهذا مما لا يختلف فيه المسلمون الحريصون على أصالة أمتهم، ولكن الاختلاف مع ذلك واقع بينهم في طرق معالجة هذا الداء وآماده الزمنية التي يقتضيها.

فبعض المتحمسين لذلك يدفعون نحو إنجازه في أقرب الآجال دفعة واحدة، ويعتبرون ذلك رهين القرار السياسي لا غير، والحال أفم لم يبذلوا أدنى جهد في توفير المضامين التعليمية البديلة التي تتسم بالأصالة

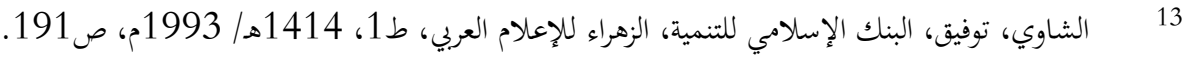

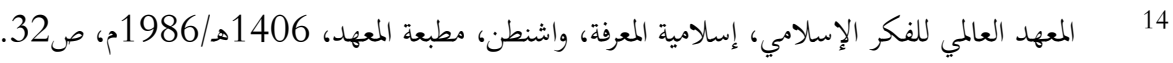


المنشودة، ويكتفون بافتراض شرط واحد هو انسجام تلك المضامين الغائبة مع مبادئ الإسلام وتعاليمه. أما من أين تأتي تلك المضامين الأصيلة، فذلك مما لمُ يدُرْ بخلدهم ولا انشغلوا به هما.

ولا شك أن إصلاح تعليم أبناء المسلمين واجب أكيد وشرط لا محيد عنه لاستعادة أصالة الأمة، ولكنه عمل مضنٍ يقتضي تضافر الجهود لتوفير المضامين الدراسية المطلوبة لكل المستويات التعليمية، ثم الشروع في الاستعاضة عن المضامين المنحولة بها، بالتدرج. وذلك يقتضي آمادا زمنية تستغرق عقودا لا تقل عن عمر جيل وقد يستغرق جيلين. ولا يتوقف على قرار حاكم حازم كما بدا لأُلكك.

وفي انتظار تحقق تلك الغاية بتمامها فإن المضامين الغربية المنحولة ستبقى جارية، مع ما يعنيه ذلك من استمرار اغتراب التعليم في مراحله العليا خاصة، واستبقاء تطعيم عقول الطلبة بمواد دراسية بجافية لتعاليم الإسلام. والأصل في ذلك المنع، لأن ما فارق تعاليم الدين الحنيف لا مقام له بين ظهراني المسلمين. ولكن بالنظر لما يترتب على مسعى التغيير الفجائي لبرامج التعليم من مخاطر قد تؤول إلى إحباط المقصد نفسه، كان لابد من سلوك فج التدرج في الإصلاح واتقاء سبل العجلة المجانبة للحكمة.

فذلك المسلك في إصلاح حال المسلمين واجب الاتباع وإن كان على خلاف الأصل، إذ الأصل نفي كل ما صادم تعاليم الشريعة. ولكن واقع الاستثناء الظري الذي تمر به الأمة يقتضي العدول عن ذلك الأصل استحسانا، لجلب مصلحة جزئية في انتظار تحقق شروط وضع الأصل في التكليف للركون إليه، بحيث لا يتحقق ذلك إلا بسلوك فج استحسان المصلحة الجزئية الظرفية لدرء تلك المفسدة بالتدريج.

وليس ذلك من باب الضرورة كما يعتقد بعضهم، لأن الضرورة طارئ داهم مفاجئ يجبر المكلف فردا كان أو جماعة على مخالفة أصل التكليف دون سابق تفكير فيه ولا استحضار لمسلك فه التدرج. أو بتعبير آخر، هو واقعة يتوجه إليها فعل المكلف دون إرادته، بخلاف التدرج المندرج ضمن دليل الاستحسان ففيه إضمار مسبق بالمخالفة بناء على استحضار ذلك النهج، وتخطيط مراد ومقصود لجلب مصلحة لا تتحقق إلا بسلوك ذلك النهج الظريف، على أمل تحقق شروط أصل التكليف للرجوع إليه مجددا. 
5. التأجيل الاستحساني وشاهد وقف الدعوة: أما مسلك التأجيل وهو المظهر الآخر من مظاهر الاستحسان كما أورده الشيخ النجار آنفا، فمن أجلى شواهده في واقع المسلمين المعاصر مسعى وقف نشاط الدعوة الإسلامية في أحد الأقطار بفعل القائمين عليه أنفسهم، لظرف طارئ يقتضي ذلك الوقف، إذا ما رأوا أن استمراره في ذلك الظرف يتهدد وجوده، وأن وقفه إلى حين، كفيل بدفع بلاء الطغاة عنه. والاكتفاء خلال ذلك بالأعمال الترتيبة الداخلية لمزيد ضبط هيكل الجماعة وضمان سلامته، أو الدخول في مناشط ثانوية قصد صرف أنظار أولي الأمر عن مسعى نشر الدعوة، 15 وإيهامهم بالجنوح للدعة. وهذا الشاهد كثير الحدوث في الواقع الإسلامي المعاصر، حيث ينتصب في بعض أمصار المسلمين حكام لا هم لهم غير ثبات سلطاهم في وضع التحلل من أعباء التكليف بتعاليم الإسلام. ولا يتوانون عن محاربة الدعوة ومحاولة استئصاها إذا ما رأوا في نشاطها الحثيث وتنامي مظاهرها تهديدا لمناصبهم. وكان في تقدير القائمين على شؤون العمل الإسلامي أن ذلك الوقف الظرفي لتوسيع نشاطهم كفيل بدرء مخاوف الحاكم وبالتالي دفع تلك المفسدة المتأتية منه. فإن حكمة الشريعة تقضي بتقرير ذلك الوقف إذاكان بجرد تأجيل لنشاط الدعوة ينقضي بانقضاء ظرفه الطارئ ثم استئنافه بجددا، وليس فيه انكفاء واستكانة دائمة تأتي على العمل نفسه بالفناء وإلا تحقق بطريق آخر نفس المصاب الذي ما اتُخذ تدبير التأجيل ووقف أصل الدعوة إلا قصد اجتنابه. بل إن ذلك واجب شرعي لا محيد عنه في مثل تلك الظروف، لأن تبليغ الدعوة والأمر بالمعروف له ضوابطه الكفيلة بالحفاظ على مبدئه، والاندفاع في استعداء الحكام أو الوقوع في مزالق تُدني آجال مصادمتهم، من شأنه أن يرتد على نشاط الدعوة الإسلامية بالخسران كما هو واقع بعض أصقاع بلاد المسلمين.

ولا يبعد قياس تأجيل نشاط العمل الإسلامي الجماعي بسلوك فج التأجيل وتأخير أهدافه، عن تأجيل دعوة الأفراد إذا كان في ذلك التأجيل تَحقق مصلحة. إذ الأمر لا يخرج في كلتا الحالتين المقيسة والمقيس عليها عن مجال الأمر بالمعروف والنهي عن المنكر، فكما أنه بخصوص الأفراد جائز، هو في حق الجماعة جائز أيضا، بل هو أولى بالجواز لعظم خطر المفسدة المترتبة على الإقدام في وضع الجماعة.

$$
15 \text { الترابي، حسن عبد الله، الحركة الإسلامية في السودان، الخرطوم، 1410هـ/ 1989م، ص 27-28. }
$$


ولكن ذلك الحكم يبقى معلَّقًا على وعي القائمين على ذلك العمل بمناط المصلحة والمفسدة وقدر كل منهما في موازنتها بالأخرى، وفي النهاية مقدار الفائدة العائدة على الجماعة المتحققة من سلوك ذلك النهج، ووعيهم بأن تقريرهم مندرج في سياق تدبير ظريف ملجئ يزول بزوال الداعي إليه، وليس مقصدا في ذاته ولا مهربا من تحمل تبعات التزامهم بالجماعة. ولكنه ليس شرطا أن يدرك أولئك أن تدبيرهم ذلك مندرج في تردي إطار دليل الاستحسان الأصولي بذاته. بل يكفي اعتقادهم بأن عملهم مشروع مطلقا، وأنه كفيل بتحقيق المصلحة. لأن المصلحة هي المقصود من التشريع وليس دليل الاستحسان أو غيره من أدلة الشرع إلا مرشدا

وكما أن ذلك الخيار التشريعي مشروع في حق الجماعة الإسلامية في وضع الاستضعاف داخل البلاد الإسلامية، فهو مشروع أيضا في حق الدولة الإسلامية في وضع ضعفها بتحاه الأمم الأخرى. ففي هذه الحال يتوقف العمل بتشريع الأصل في كثير من الوقائع، في علاقات الدولة الداخلية والخارجية، لأن أصل التشريع فيها قائم على أساس الشوكة والصولة، لا على أساس الضعف والعجز عن أصول التكليف.

ففي علاقاها الداخلية تتقوى الطوائف الدينية المخالفة بحكم ارتباطها العقدي بالأمم الأخرى وولائها لها، فيتعذر إجراء أحكام أهل الذمة بحقهم في غضون ذلك الظرف، لما يؤدي إليه إجراء ذلك الأصل من استعدائهم في وضع هم قادرون على إهاك الدولة الإسلامية داخليا، ومزيد إضعافها بفضل قوقم الذاتية ودعمهم الخارجي. وهو إجراء ظريف يلزم فيه مخالفة أصل التشريع في معاملة أهل الذمة مستحسَن للحفاظ على وجود الدولة الإسلامية. وخلاف ذلك المسلك قد يؤول إلى انتفاء أحكام الشريعة بالكلية بانتفاء الدولة القائمة عليها. فتأجيل أحكام الأصل في ذلك الجانب الضيق من التشريع، والركون فيه إلى خلافه إلى حين، أحق من كل وجه من ضياع دولة الشريعة بسبب الإصرار على الأصل في غير محله.

وفي علاقاتما الخارجية، لا يتسنى لدولة الإسلام في مراحل ضعفها أن تحمي الدعاة المتطوعين لتبليغ

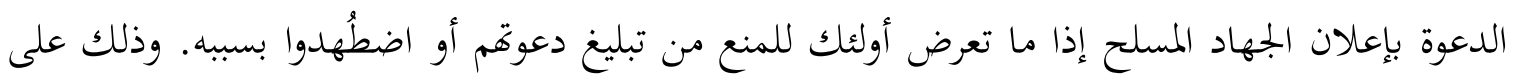
خلاف الأصل في التشريع، إذ الأصل قتال كل من يمول دون بلوغ الدعوة سواء كان داخل بلاد المسلمين أو خارجها. وقد خولف هذا الأصل ظرفيا لعدم القدرة عليه وملا يؤول إليه من مخاطر، على سبيل التأجيل لا 
بقصد الوقف المؤبد وإلا كان حكما مخالفا للشريعة نفسها لا يجوز الركون إليه. ولأنه في هذه الحال منع لفرض من فرائض الإسلام وليس مجرد تدبير تأجيلي له اقتضته المصلحة. 16

\section{الاستحسان ومظاهر التضامن الاجتماعي}

لا ريب في أن كل مظهر من المظاهر الاجتماعية التي تتضافر فيها جهود الأفراد على مقصد فيه خير

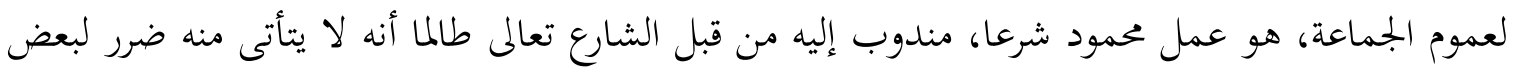
الناس، لقوله تعالى: لهوتعاونوا على البر والتقوى ولا تعاونوا على الإثم والعدوان (المائدة: 2). فما من شك في أن مظاهر التعاون والتكافل الاجتماعي هي من وجوه البر المدعو إليه بصريح الآية. لكن مع ذلك الوضوح في المقصد وجلاء تحقق المصلحة فيه عمليا، فقد ظهر في الأدب الأصولي الإسلامي إشكال نظري، مفاده أن بعض تلك الوجوه من المعاملات مشروعة على خلاف الأصل، بما يعني أن الأصل فيها المنع، وإنما سُمح بها استثناء من قواعدها الممنوعة دفعا للمشقة على المكلفين المتأتية من طرد حكم القاعدة، أو تعقبا لمصلحة تتحقق فيها دون نظائرها.

1. شاهد القرض: ولعل أظهر شاهد لذلك قديما هو مثال القرض الذي اعتبره عامة الفقهاء مندوبا

إليه على خلاف الأصل، بدعوى أنه راجع لقاعدة الربا والأصل فيه المنع وإنما اسُشني هذا الفرع منها رفقا بذوي الفاقة من المكلفين. وفي تحرير ذلك أورد الإمام الشاطبي قوله بعد تأكيده أن قاعدة الاستحسان مبنية على ما عُلم من مقاصد الشارع تعالى القاضية بالعدول عن القياس إذا أدى إلى فوت مصلحة: "وله في

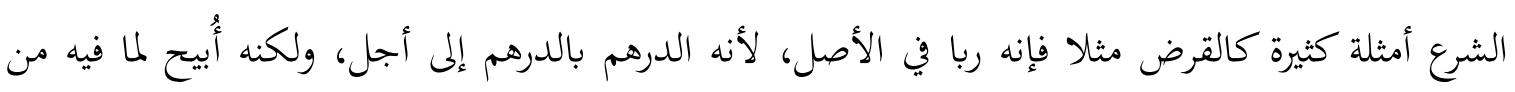
المرفقة والتوسعة على المحتاجين، بجيث لو بقي على أصل المنع لكان في ذلك ضيق على المكلفين". 17

شاهد ذلك من سيرة الرسول الكريم صلح الحديبية، فهو يمثّل تأجيلا لفريضة قتال مشركي مكة مع القدرة عليه، وهو تأجيل اقتضته

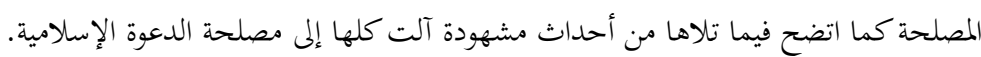

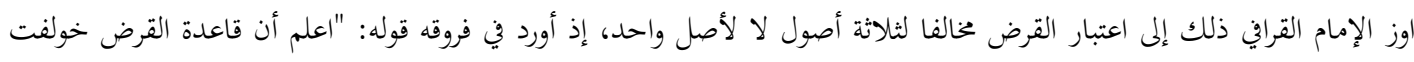

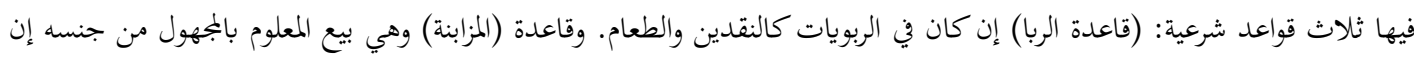

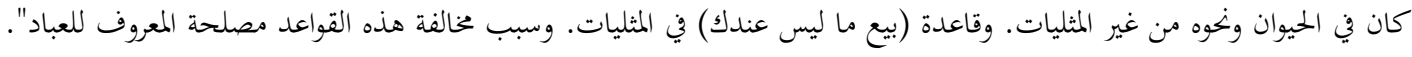

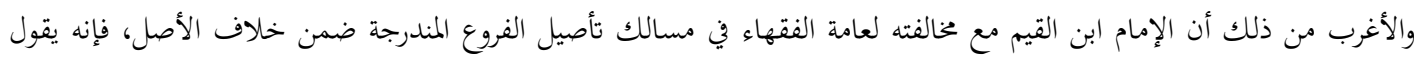

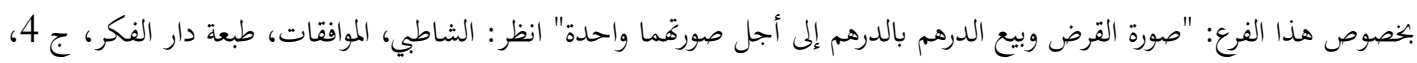


وهذا المنهج في عملية ضبط الفروع وإرجاعها إلى قواعدها ينبئ بوجود خلل في بعض مسالك التقعيد وما يعقبه من إلحاق الفروع بأصولها لدى الكثير من الفقهاء. ويظهر ذلك جليا في هذا المثال، وإلا فما وجه صلة القرض بأصل منع الربا، والحال أن الربا لغة وشرعا قائم على معنى الزيادة التي هي علة التحريم، 18 وهي معدومة في القرض. ذلك أن إقراض الدرهم (أي الأوراق النقدية المتداولة في أيدي الناس) بمثله خاليا من أي تربي زيادة على رأس المال المقرَض إنما المقصود به التوسعة على المحتاج ومؤازرته، طالما أنه مطالَب بإعادة نفس القدر دون زيادة، فالرفق بالمقترض هو الدافع إلى الإقراض، ونيل ثواب الله في الآخرة هو المقصد منه، وليس للمقرٍِ منفعة دنيوية البتة، ولا يحضره لحظة الإقراض الحصول على غير ما أقرض، ولا المقترض أيضا يهضره ذلك "فالمقرض يقرضه ما يقرضه لينتفع به ثم يعيد له بمثله، فإن إعادة المثل تقوم مقام إعادة العين... فليس هذا من باب البيع فإن عاقلا لا يبيع درها بمثله من كل وجه إلى أجل، ولا يباع الشيء بجنسه إلى أجل إلا مع اختلاف الصفة أو القدر".

كما لا يصح اعتباره راجعا إلى ربا البيوع -حتى ولو كان قرض أعيان (عروض بتحارية) بمثلها لا درهم بمثله- بدعوى أنه من عقود المعاوضات. لأن معنى المعاوضة هو تبادل مِلك يستفيد منه كل من الطرفين بحصوله على العوض الذي يحتاجه، فتتحقق منفعته بامتلاك ذلك العوض، فالمنفعة فيه متبادَلة. بخلاف القرض فالمنفعة فيه راجعة لطرف واحد هو المقترِض، الذي حصل على مال يفرّج به كربته لم يكن في حوزته

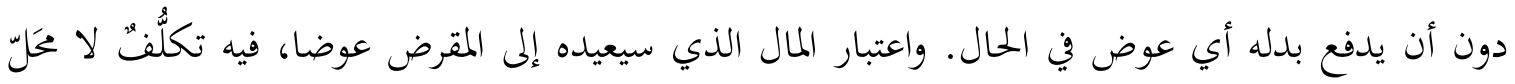
له، لأن المال الذي هو محل العقد هو نفسه انتقل من ملك الدائن إلى ملك المدين ثم عاد إلى الدائن مجددا. فصفة العملية هنا هي التداول وليس التبادل. بدليل أن الدائن لم يستفد من تلك العملية شيئا، ولا قصد الربح الذي هو غاية كل تبادل بتحاري، بل غايته في هذه العملية هي مساعدة المُتاج في الدنيا ونيل ثواب الله تعالى في الآخرة، وليس هذا ببدَل في عرف الناس، ولا يُعَد صفقة بتحارية بالمعنى الذي يقتضيه نشاط

ص 117، والقراف، الفروق، بيروت، دار الكتب العلمية، ط1، 1998، ج 4، ص 3، وابن قيم الجوزية، إعلام الموقعين، بيروت، دار

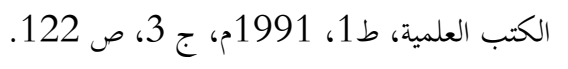

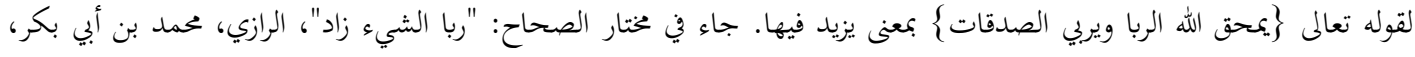

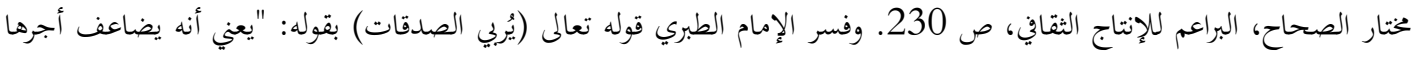

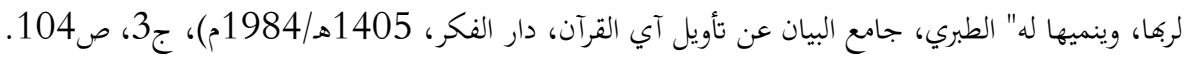


المعاوضات المالية. وإنما الصواب فيه أنه عقد تبرع لا صلة له بالمعاوضات المالية التي تكمن فيها شبهة الربا. ومن تَّهّ فهو وجه تعاملي داخل في دائرة الأصل ولا علاقة له بخلافه. فاعتباره إذن جائزا على وجه الاستحسان والأصلُ منعُةُ، فيه نظرَّ ويحتاج إلى مراجعة. وما قرره الإمام ابن تيمية في هذا الفرع 19 وفي الكثير

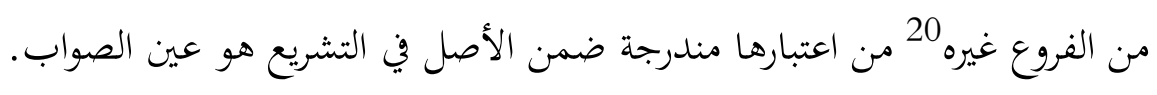

والخَطْبَ في ذلك قد يلوح يسيرا طالما أن الحكم الشرعي وهو ثمرةُ الاجتهاد كله وغايتُه المقصودةُ واحلُ،، وهو الندب بخصوص هذا الفرع، باعتبار أن الخلاف فيه نظري. ولكن الأمر ينحو منحى أكثر خطورة إذا بتحاوز الحلافَ النظريَّ، إلى الأحكام الفقهية العملية نفسِها، وطُبّق هذا المنهج على وجوه المعاملات الاجتماعية المهمة والوقائع الجارية في أنظمة المجتمع باطراد، التي تتحقق فيها صفة التآزر والتضامن الاجتماعي في هذا العصر، فأُخرجت من دوائرها الشرعية الراجعة إليها بالنظر أصالةً، واعتُبرت منوعةً شرعًا، أو جائزة على وجه الاستثناء من قواعد التشريع العامة، وأن الأصلَ فيها المنعُ، مع ما فيها من مصلحة ظاهرة لا تكاد تشوبها شائبة المفسدة، وخير عميم يرجع على أفراد المجتمع عامة بالفائدة، من مثل نظام التأمين ونظام التعليم المجاني والخدمات الصحية المجانية وقطاع النقل موحد التسعيرة.

وبيان ذلك من الوجهة الأصولية المعهودة لدى عامة الفقهاء، أن تلك المظاهر الاجتماعية لا يُنظر إليها من حيث مقاصدها ومآلاقا وما تحققه من مصلحة عند إلحاقها بأصولها، بدعوى أن التعليل لا يكون بالمقصد لعدم انضباطه، وإنما يُنظر إليها باعتبارها لا تنفك عن شائبة الغرر والجهالة وفق هذا المنهج، والأصل فيها المنع، وإنما جازت للحاجة ودفع المشقة، لا لما تحققه من مصلحة اجتماعية عامة.

جاء في فتاوى الإمام ابن تيمية قوله: "ومن قال: القرض خلاف القياس قال: لأنه بيع ربوي بجنسه من غير قبض. وهذا غلط، فإن

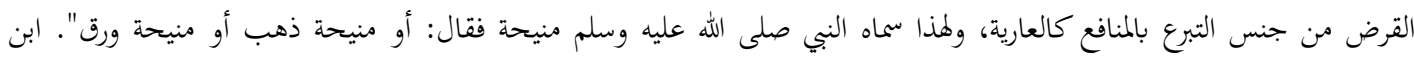

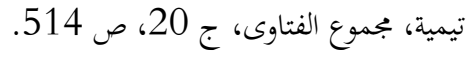
مثل المضاربة والمغارسة والمساقاة والمزارعة... وهي خارج صنارئ دائرة التضامن الاجتماعي المقصود في هذا المبحث، ولكنها تندرج في نفس المنهج في معالجتها الأصولية. 
2. شاهد نظام التأمين: شاهد ذلك من الناحية العملية أن نظام التأمين 21 بأنواعه التعاوني 22 منه والتجاري والخاص، هو مظهر من مظاهر التضامن الاجتماعي، لا ينفك عن ذلك النهج، لأنه لا يخرج عن كونه عقدا بين المؤمّن والمستأمَن سواء كان بالخيرة والتراضي بين المتعاقدين كما في التأمين التجاري، أو بالالتزام المفروض بالقانون كما في تأمين وسائل النقل. والإشكال الوارد عليه بحسب ذلك النهج الأصولي أن المستأمَنين يلتزمون بدفع مقادير مالية متساوية غير عارفين بما يخبع لهم القدر، لأن بعضهم قد يُصاب عمله المؤمَّن بضرر ما قبل انقضاء الحول الأول من التزامه بالدفع، فيعود عليه ذلك بفائدة مالية تساوي أضعاف القدر الذي دفعه، لجبر الأضرار الحادثة في نشاطه التجاري أو الصناعي أو في سيارته بحسب نوع التأمين. بخلاف غيره فإنه يداوم على التزامه بالدفع طوال حياته دون أن تتعرض متلكاته المؤمَّنة لأي ضرر، فلا يستفيد من التزامه شيئا، بما يعني أن التزامه ذلك إنما عاد على غيره بالنفع ولم يرجع إليه بشيء. وفي ذلك تلك نوع من الغرر لا يفيء إلى قاعدة العدل الفردي، وفق المنظور التأصيلي المعهود لدى جمهور فقهاء الشريعة الإسلامية.

وكان من الحق معالجة مثل هذا النوع من العقود من منظور مخالف، هو منظور الإمام ابن تيمية، بالنظر إلى المصلحة العامة المتأتية من ذلك العمل. وهي مصلحة ظاهرة متحققة الرجحان إذا ما استُحضر فيها مبدأ العدل الجماعي دون الفردي، حيث تنتفي ملامح الغرر بالتأكيد. 23 لأن المصلحة الراجعة للبعض

ليس مناط اهتمام هذه الدراسة تتبع مواقف الفقهاء وحججهم، فلينظر في ذلك محمد بن ابراهيم، الاجتهاد وقضايا العصر، تونس، دار

$$
\text { التركي للنشر، 1990م، ص } 113 \text { وما بعدها. }
$$

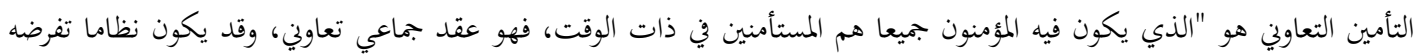

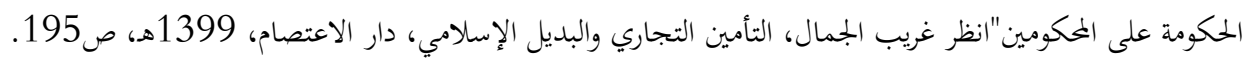

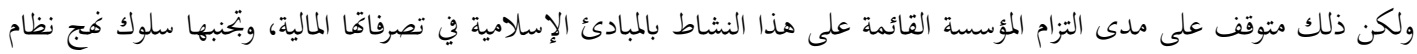

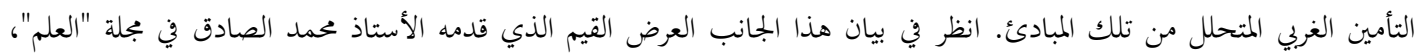

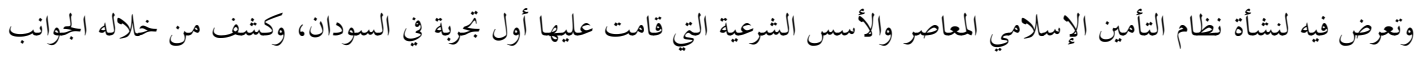

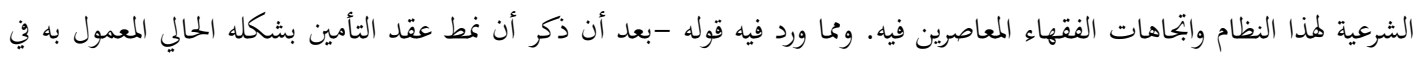

$$
\text { الأنظمة الغربية يتناف مع ضوابط الشريعة الإسلامية- }
$$

..."this is the opinion of the majority of Islamic jurisprudents who are opposed to Western oriented insurance contract and practice because: 1. It includes al-gharrar, 2. It is based on the theory and practice of riba (interest), 3. It is a sort of gambling, Sadik, Mohamed, 
لا يتضرر من جرائها البعض الآخر وإن لم تعد عليه بفائدة محسوسة. بل يكفي من التزم ولم يتقاض أن كان سير عمله محفوفا بالشعور بالطمأنينة المتأتية من ضمان الجبر في حال لحوق الضرر بما من شأنه أن يدفع هاجس الخوف المعيق للعمل، وفي ذلك وحده خير لا يقدر.

وبالتأكيد أنه لو سئل أصحاب هذا المنهج في التأصيل عما إذا ابتُلي أحدهم بمصيبة أتت على كل ماله أو بعضه وتمدده الفقر بعد الغنى، ثم رق بحاله أهل عشيرته أو قريته أو نظراؤه في مهنته فالتزموا بدفع ما يزيل ضرره على سبيل التضامن الإسلامي بطريقة التأمين نفسها. فإنم لن يترددوا في تقرير ندب ذلك

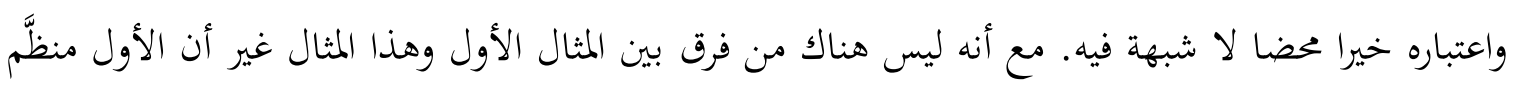
مقنن سلفا، والثاني جاء عرضا بغير سابق تدبير وتقدير. وليس ذلك بفرق معتبرَ في العدول عن الحكم إلى غيره في الشرع. بل العكس أوْلى، وهو أن كل مظهر من مظاهر التضامن الاجتماعي المنظم هو أولى من الوقائع التضامنية العارضة غير مضمونة الدوام، لأن نجاحها رهين دوافع الأفراد الذاتية، فضلا عن تراوح الظروف الطارئة بينهم بما يبعل قدر التضامن فيهم ضعيفا في تلك الحال. خلافا للالتزام الجماعي المقنن فلا تطرأ عليه تلك المنغصات ويتحقق فيه مقصد التضامن بالتأكيد. فكيف يمكن اعتباره والحال تلك غير جائز أو جائزا على خلاف الأصل وفيه كل ذلك النفع!؟

ولكن ذلك المقصد لا يمكن البوء إليه في حال التمسك بمنهج الفقهاء، بما يعني أن سداد الثمرة الفقهية رهين سداد منطلقاقا الأصولية، يخضر بحضورها وقد يغيب بغياها. ومصداق ذلك بخصوص هذا الفرع الفقهي أن الفقهاء المعاصرين قد اختلفوا في حكمه بناء على اختلافهم في منطلقاتم الأصولية النظرية، فقال بعضهم بجوازه على الأصل، وقال آخرون بجوازه على خلاف الأصل، وقال فريق ثالث بحرمته مطلقا. ومن قال بجوازه على الأصل الفقيه الشيخ مصطفى أحمد الزرقاء. فقد جاء عنه قوله: "بالنظر إلى غاية عقد التأمين -لا بالنظر القاصر إلى محله المالي - ليس فيه غرر أصلا حتى بالنسبة إلى المستأمن". 24 بل هو

"Islamic Insurance System as Practised by the Islamic Insurance Company limited, Al-Ilm, Vol (15), 1995".

$$
\text { الزرقا، مصطفى أمد ، نظام التأمين، حقيقته والرأي الشرعي فيه، بيروت: مؤسسة الرسالة، 1، 1404ه/1984م، ص161. }
$$


يتجاوز هذا الحد في البرهنة على جوازه ليقرر أن "عقد التأمين هو الذي يزيل حالة الغرر من الوضع

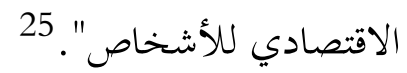

وواضح من خلال وضْم نظر مخالفيه المنصب على محل العقد نفسه دون غايته بالقصور، أنه يقصد التعريض بأصحاب منهج فقهاء العلة المنضبطة الذين تمسكوا بتطبيق صور القواعد الشكلية المعلومة لديهم سلفا، 26 والحمل عليهم لإغفاهم غايات العقد ومقاصده. في حين يختار هو سلوك فج المناسبة المعلل بالحكمة، ولا يرضى التقيد بشرط انضباط العلل. وقد صرح بأصله هذا في تعقيبه على تعليق الإمام أبي زهرة27 المانع من قياس المناسبة، بقوله: "إن من المقرر في علم أصول الفقه أن طريق القياس الذي إليه يرجع الفضل الأعظم في تضخم الفقه الإسلامي هذه الضخامة لا يجب فيه الاتحاد المطلق في الصورة بين المقيس والمقيس عليه. وإلا لما كان عندئذ حاجة لإجراء القياس إذ يكون المقيس عندئذ فردا من أفراد المقيس عليه. بل يكفي في القياس التشابه بين المقيس والمقيس عليه في نقطة ارتكاز الحكم ومناطه وهي العلة. وهذا ما

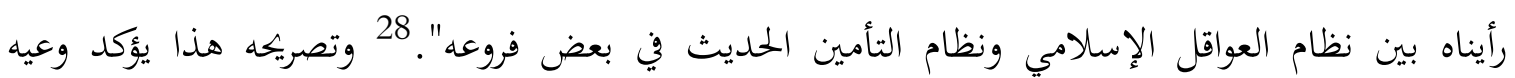
لمنطلقاته الأصولية في الاجتهاد، وأن سلوك فج المناسبة في التعليل هو اختياره في تقرير أحكام الفروع. وقد طبقه على فرع عقد التأمين فوصل به إلى حكم الإباحة بغير تحفّظ. وهذا هو نفس فج الإمام ابن تيمية في القياس الفقهي الذي توسع بفضله فقه المعاملات لدى الحنابلة واكتسب مرونة غير معهودة لدى المذهب قبله ولا لدى غيره من المذاهب بعده.

في حين وقف بعض الفقهاء الآخرين موقفا مقابلا تماما، فقالوا بحرمة عقود التأمين غير التعاوني، وعلى رأسهم الإمام الفقيه محمد أبو زهرة الذي قال: "أن كون عقد التأمين عقد معاوضة لا يمنع منه معنى

$$
\begin{aligned}
& 25 \\
& 2627 \\
& 27 \\
& 28
\end{aligned}
$$


القمار ... ولذا نرى الشبهة قائمة، بل نرى أن مع القمار ربا مؤكدا في حال ما إذا مات المستأمن قبل المدة، لأنه يدفع نقدا قليلا، ويأخذ بدله نقدا كثيرا، وهذا بلا ريب ربا ومعاملة لم يحلها أحد من الأئمة". 29 وهو بذلك يخالف الشيخ مصطفى الزرقاء في تقرير الحكم تمام المخالفة. ومخالفته له مردها اختلافه معه في الأصول النظرية، إذ أن منهجه الأصولي يقضي بإعمال العلة المنضبطة ورفض قياس المناسبة القائم على التعليل بالحكمة. وهو أيضا مدرك تمام الإدراك لمنطلقاته الأصولية. وقد صرح بأصله في رده على حجج الشيخ الزرقاء بقوله: "...أما أن عقود التأمين ليس فيها صد عن ذكر الله وعن الصلاة وليس فيها إثارة للحقد والحسد والبغضاء فنقول فيه: أن هذه حِكم وأوصاف مناسبة، وليست عللا يسير معها الحكم طردا وعكسا، بحيث يكون التحريم إن وُجدت، ويكون الحل إن لم تكن". 30

وبذلك يتبين أن حكم هذا الفرع هو الجواز وفق الأصل في التشريع عند الفريق الأول، والتحريم وفق الأصل عند الفريق الثاني. في حين توسط بعض الفقهاء المعاصرين، فقالوا بجوازه على خلاف الأصل، لأن عقد التأمين عندهم لا يخلو من شائبة الغرر، ولكنه غرر معفو عنه دفعا للحرج والمشقة وتيسيرا على المكلفين مراعاة لحاجتهم لهذا النمط المهم من التعامل. ومن هؤلاء الفقيه الشيخ عبد الله بن زيد آل محمود، 31 فقد أورد في تقرير جواز عقود التأمين قوله: "الذي ترجح عندنا هو أن التأمين على حوادث السيارات والطائرات

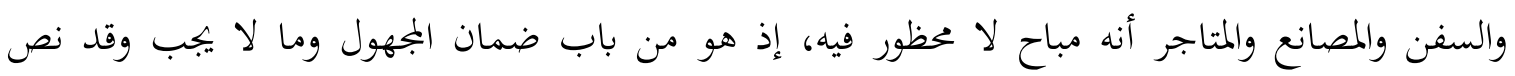
الإمام أحمد ومالك وأبو حنيفة على جوازه". 32

$$
\begin{aligned}
& 29 \\
& 30 \\
& 31
\end{aligned}
$$

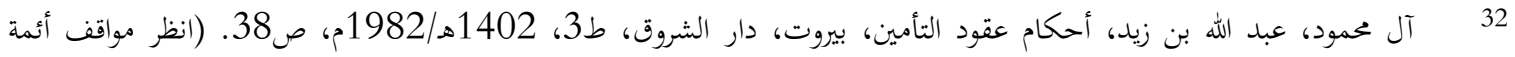

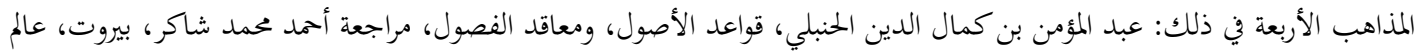

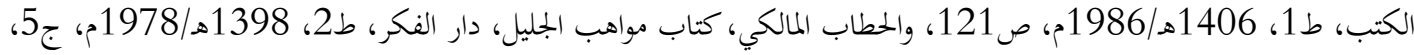

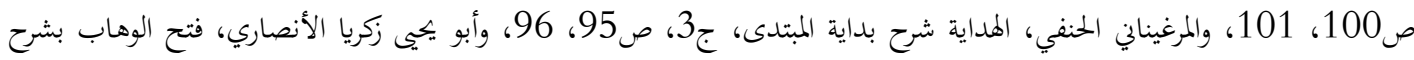

$$
\text { منهج الطلاب، دار الفكر، ج1، صلم ص } 215 .
$$


والشيخ عبد الله بن زيد لا يصرح بأصله النظري خلافا لسابقيه، ولكن تقريره لحكم الجواز مع إقراره بوجود شبهة الجهالة في عقود التأمين يكشف منهجه المتمثل في مسلك خلاف الأصل. فطالما أن الجهالة موجودة في هذا الفرع، فإن حكم الجواز وارد عنده على خلاف الأصل. لأنه لا أحد من الفقهاء ينكر أن الأصل في عقود الجهالة المنع. وهو يصرح بنسبة هذا الفرع لعقود الجهالة في قوله: "وليس فيه من المخذور سوى الجهالة بالأضرار التي قد تعظم في بعض الأحوال فتقضي بهلاك بعض النفوس والأموال وقد لا تقع بحال. وهذه الجهالة مغتفرة فيه كنظائره من سائر الضمانات، فقد ذكر الفقهاء صحة الضمان عن المجهول

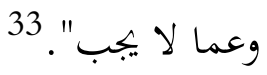

وبذلك تتبين ملامح المناهج الأصولية الموروثة في التعليل والتأصيل، من خلال الحركة الفقهية المعاصرة، و تأثيرها فيها، رغم وضوح أثر الأسباب التاريخية الظرفية في تشكيل تلك المناهج، وميلها بالقواعد الأصولية نحو الإغراق في التنير والمشاحة في رسم الضوابط الفنية الشكلية المعيقة لعملية الاجتهاد. وذلك مما لا طاقة لنشاط الاجتهاد الفقهي المعاصر بتحمله. لأن طبيعة وقائع العصر تقتضي فج التيسير، وكثافة الضوابط الفنية من شأفها أن تعسر على الفقهاء مسالك تقرير الأحكام المناسبة.

3. شاهد وحدة التسعيرة في وسائل النقل: وشبيه بالمثال السالف في وجه الغرر شاهد وحدة التسعيرة في وسائل النقل، خاصة إذا كانت على ملك الخواص. ووجه الاشتباه فيها وفق المنهج التأصيلي السالف أن شركات النقل العمومي تتقاضى حافلاهما مقدارا ماليا موحدا من مبدأ الرحلة إلى منتهاها خلال رحلاتحا المتوالية في الخطوط الحضرية خاصة، دون مراعاة قدر المسافة التي يستغرقها الراكب، فقد يمتطي الحافلة في موقف وينزل في الذي يليه، وقد يمتطيها في أول موقف ولا ينزل إلا في آخر مطاف الرحلة. وهو في كلا الحالتين يدفع القدر المالي نفسه المقرر سلفا.

فبالتزام منهج الفقهاء المذكور لا يمكن أن يكون هذا النمط من المعاملة المعاصرة جائزا إلا على خلاف الأصل في التشريع استحسانا، والأصل منعه لشبهة الغرر فيه التي تقضي باستفادة الواحد على لى خلاف غيره بما يستحيل ضبطه وفق هذا النمط التعاملي. وكان الأصل عندهم أن تُعيَّن لكل مسافة بين 
الموقفين تسعيرة مقدرة بطول تلك المسافة التماسا لمقصد العدل. وبما أن ذلك المطلب من شأنه أن يسبب حرجا شديدا وارتباكا معيقا لسير العمل، فقد تُسومح في إجراء ذلك النمط الموحد على خلاف الأصل دفعا للمشقة وجنوحا للتيسير في شؤون الناس.

ومقاربة هذا النمط التعاملي المعاصر بنظائره في التراث الأصولي يحيل الواقعة إلى شاهد دخول الحمام قديما، فهو المثال الأشبه بهذه الواقعة، وقد رأى عامة الفقهاء جوازه على خلاف الأصل بدعوى كمون شبهة الجهالة في الأجر والزمن المقضي ومقدار الماء المستعمل. ولكون ذلك مما يستحيل ضبطه مع حاجة الناس الأكيدة إلى دخول الحمام، فقد قالوا بجوازه دفعا للحرج على خلاف الأصل في التشريع، إذ الأصل منعه لشبهة الغرر فيه، وما جاز عندهم إلا عرضا، استثناء من قاعدة منع عقود الغرر لذلك السبب المخوج. 34 بخلاف المنهج التأصيلي القائم في تعليله على مقاصد الشريعة وِكمها، فإنه يقضي بخلاف ذلك، باعتبار أن أصل التضامن الاجتماعي المققق لمبدأ العدل الجماعي الأسمى يقضي بأن هذا الوجه من التعامل اليومي جائز على وفق الأصل في التشريع ولا صلة له بخلاف الأصل، ولا هو داخل في دليل الاستحسان، لأن المصلحة فيه متحققة للجميع، وكوها محل تفاوت مع اتحاد الأجر لا يقوم شبهة لإخراجه من دائرة الأصل، نظرا لأن تلك المصلحة متداولة، فالذي يمتطي الحافلة لمسافة قصيرة ويدفع مالا أكبر من قدر منفعته هو نفسه يمتطيها مرة أخرى لمسافة طويلة ويدفع ذات المبلغ المالي، فيعود عليه اليوم ما خسره بالأمس. كما في ذلك نفع آخر وهو أن الذي يمتطي الحافلة لمسافة قصيرة إنما يترك مكانه لراكب جديد يسدد بدوره

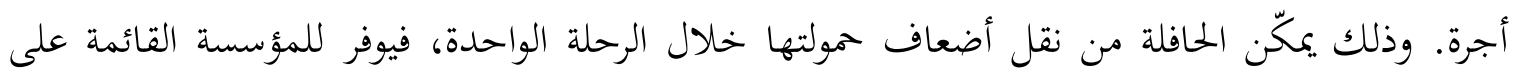
ذلك النشاط ربحا كبيرا يدفعها إلى الرضا بتقرير معلوم زهيد للتذكرة الموحَّدة -قد يقارب قيمة أدنى مسافةحفاظا على استمرار نشاطها واستبقاء لذلك المورد. وفي ذلك مصلحة للجميع. وذلك كله بفضل ذلك

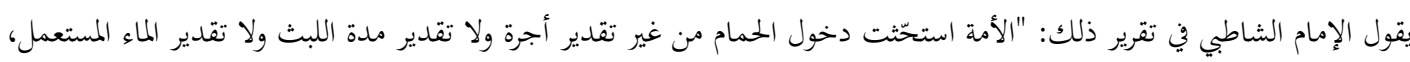

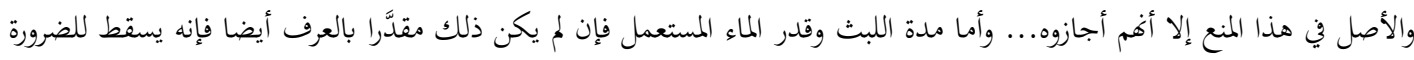

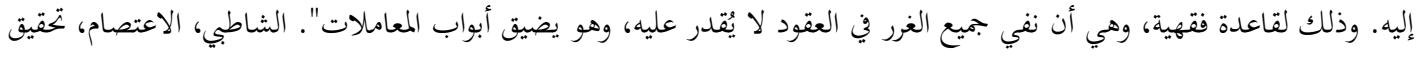

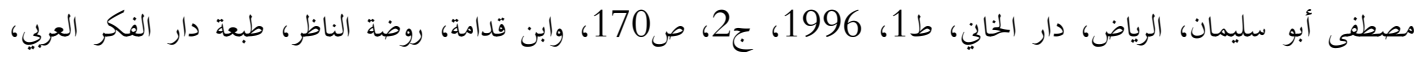


المظهر السامي من مظاهر التضامن الاجتماعي المحقَق عمليا، وإن لمُ يَعِع أفراد المجتمع المزاولون له والمنتفعون به حقيقته نظريا.

4. شاهد مجانية التعليم: وهذا المثال مع أن درجة الاشتباه فيه أدنى من سابقيْه لأن التعليم عادة ما يكون مؤما، فإنه مندرج في الإطار السابق نفسه، لأنه لا ينفك بدوره عن مناط الغرر ولا تتحقق فيه صفة

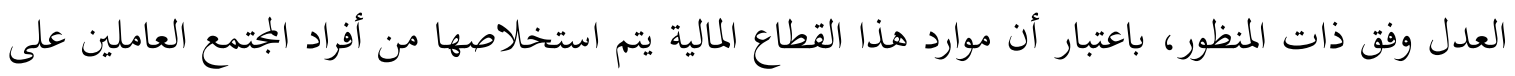
السواء، والحال أن أولئك متفاوتون في مردود الفائدة التعليمية، فمنهم من استفاد كثيرا لطول فترة تحصيله العلمي، ومنهم من لم يستفد تماما لعدم التحاقه بصفوف الدراسة. وبين هذا وذاك درجات يتعذر ضبطها. ومن أولئك من أوتي من البنين من استفادوا من التعليم وفرة، ومنهم من لم يؤت، وبينهما تفاوت لا يقبل الحصر أيضا. وفي ذلك منافاة لمبدأ العدل الفردي، يقتضي منع ذلك السلوك وفق ذات المنحى في الاجتهاد. ولكن ذلك الحكم قد عُدل عنه إلى الجواز بسبب تعذُّرِ ضبْطِ نصيبِ كل واحد من الفائدة ليُقعَّر بها نصيئه من الأداء المالي في دائرة المجتمع المتشابك في موارده ومصارفه. ولا يُنظر فيه إلى اعتبار عموم المصلحة العظيمة المتأتية منه، أصلا غالبا على تلك الشوائب الموهومة، حتى يكون الأصل في هذا القطاع الجليل الوجوب، في ربوع أمة تحض شريعتها على العلم وتعتبره فرضا عينيا.

ومردّ ذلك أن المصلحة التي هي حكمة الشريعة لا تصلح عندهم علةً في تقرير أحكام الفروع والوقائع، ولا في ضبط الأشباه والنظائر في دوائرها التي تسمى أصولا، بدعوى أها لا تنضبط. وما أخرجها الإمام ابن تيمية من دائرة خلاف الأصل وأعادها إلى القاعدة العامة في التشريع، إلا بهدم ذلك الأساس النظري الذي انطلقت منه بتوسيع دائرة القياس من المعنى المنضبط إلى أفق الحكمة.

وبسلوك منهج الإمام ابن تيمية الأصوب يتسنى الخروج من هذا المأزق الأصولي الذي يمثل شبهة لا تليق بالشريعة الغراء. ومن ثم يتبين أن نظام التعليم المجاني لا يدخل البتة في دائرة خلاف الأصل. وإنما مقامه أصل التشريع لا الاستثناء منه، لأنه خير محض، وما قد يلوح فيه من غرر وفقا لمعيار العدل الفردي لا يقوم

ولا يمكن الادعاء أن هذا الوجه من التعامل على خلاف الأصل بالنظر إلى أنه مبادلة مال عيني بمنفعة والمنفعة معدومة فلا تجوز أصالة قياسا بالإجارة، لبطلان هذا الأصل القاضي بإلحاق المنافع بالمعاديم. 
شبهة لاعتباره داخلا في عقود الغرر ولا لاحقا بخلاف الأصل. لأن ميزان العدل الجماعي هو الذي جاءت شرائع الأنبياء لتقريره، وهو المعيار الحقيقي لدرك الأصول في قطاعات الخدمات الاجتماعية العامة. خلافا لذلك المعيار الفردي فهو قاصر على شؤون الفرد في مصالحه الخاصة أو معاملاته المالية المحدودة، ولا يجدر الاحتكام إليه في القضايا الاجتماعية المترابطة، لأن هذا النمط من القضايا لا تلازم فيه بين قيمة العدل وقيمة المساواة. والإصرار على تعقّب قيمة العدل المطلق من خلال التماس مبدأ المساواة، هو منهج مغلوط في شبكة العلاقات الاجتماعية العامة، من شأنه أن يؤول إلى تلك الأحكام المختلة. فضلا عن كونه منهجا مثاليا لاحظّ له في واقع الناس ولا يعود عليهم بفائدة تُرجى.

5. شاهد الحدمات الصحية الجمانية: وشبيه بسابقه قطاع الخدمات الصحية المجانية، فهو لو نُظر إليه

من خلال النهج الأصولي الموروث لدى الفقهاء، لحُكم بجوازه على خلاف الأصل في التشريع، مع ما فيه من مصلحة جماعية لا تُقدّر بثمن، وفائدة تعود على أفراد المجتمع كافة. وإن كانت تلك الفائدة متفاوتة بين أفراده ولا يمكن ضبطها لتقدير واجب كل منهم بحسبها، فإن ذلك لا يقوم ذريعة لاعتباره مخالفا للقياس القاضي بالعدل المطلق في الحقوق والواجبات.

ذلك أن الخدمات الصحية لا يستفيد منها من ليس له أطفال أو له منهم القليل بمثل ما يستفيد منها من أوتي منهم كثرة، فضلا عن أن أولئك منهم من ابتُلي بكثرة الأمراض، فيحتاج إلى رعاية صحية وخدمات كثيفة تتطلب مصاريف قد تكون باهظة جدا، يتحملها عنه المجتمع ولا يسدد منها شيئا. ومنهم من رُزق دوام الصحة فلا يكاد يستفيد من تلك الخدمات شيئا، ومع ذلك يكون نصيبه من تحمل مصاريف الخدمات الطبية نظير الأول. فهل يستقيم ذلك مبررا لإخراج تقرير جواز هذا القطاع من دائرة الأصل إلى خلافه، مع ما فيه من صلاح ظاهر ومصلحة جمة!؟

لا شك أن سلوك هذا الفرع الفقهي مسلك التنظير الأصولي الموروث لدى عامة الفقهاء فيه إجحاف مخالف لحكمة الشريعة. لأن هذا النظر لا يخرج عن كونه إعمالا آليا لقواعد نظرية شكلية، تغيب فيه الأبعاد المقصدية في التشريع. وتلك صفة سلبية في بعض أطوار كل تشريع تدفع إليها المشاحة في التقنين والضبط الفني والتظير على حساب المقاصد ومآلات الأفعال، كان المفروض ألا ينحدر إليها نشاط الاجتهاد في 
تاريخ التشريع الإسلامي، لأنه تشريع في أصله سماوي، ولكنه لم ينفك عنها لقيامه على مبدأ الابتلاء في الاجتهاد التكليفي المتصف بالنقص والتقصير. وذلك وضع يقتضي المراجعة والتعديل لتصويب حركة الاجتهاد الفقهي في هذا العصر وإخراجها من مأزق التزام القواعد الشكلية المعيقة لتحقيق المصالح.

\section{خاتمة}

تبين من خلال ما سلف عرضُه أنه -وفق المنظور الأصولي المتعارف، وطريقة الفقهاء التقليدية الغالبة في معالجة القضايا الفقهية- لا يمكن التوصل اليوم إلى تقرير الأحكام الشرعية المناسبة بخصوص الكثير من الوقائع الاجتماعية الجارية رغم وضوح صلاحها لعموم المجتمع، نظرا لما قد يتراءى من غرر أو جهالة في استحقاق تلك المصالح من قِبَل البعض دون غيرهم أو تفاوقم في استحقاقها. مما لا يعدو كونه غررا موهوما - إذا ما قيس بمقدار المصلحة العامة- لا يجدر حرمان العامة منها بمانعه، أو هي جهالة في تقدير الناظر لفرد بعينه، متجاهلا أن المجتمع هو أفراد تعارفوا على الاجتماع وتلك الجهالة من توابع اجتماعهم، وفي تضامنهم مصلحة لمم لا محالة، ولا مبرر إذن للتردد في تقرير شرعية تلك الأنماط من التعامل الاجتماعي والوقائع الجارية فيه بلا انقطاع، لظهور صلاحها، ثم لكوها تتساوق مع مقاصد الدين الإسلامي الحنيف الداعي إلى التضامن والتآزر بما يدعمه ما لا يكاد يتناهى من الأدلة الشرعية التفصيلية، باعتباره مقصدا شرعيا عاما. ولا حاجة للإلحاح في التماس أدلة نصية شاهدة على مشروعية كل فرد من أفراده على التفصيل، أو النبش في أقوال السابقين واستبطانا لمحاولة استشفاف ما قد تفيده في الحكم على تلك الفروع الفقهية مع كوغا مستحدثة لا شبيه لها من كل وجه في واقع أعلام السالفين، ولو قُدّر لهم معايشتها لما ترددوا في الدعوة إليها والتمكين لها في مجتمع المسلمين اليوم، لما فيها من خير ظاهر لا مراء فيه. بل هو خير مخض لا تشوبه

مفسدة. كيف لا وقد تعارفوا على ترجيح المصلحة الغالبة المشوبة بمفسدة مرجوحة، وهذه لا مفسدة فيها! بل إن إدراج مثل تلك القضايا الاجتماعية الجارية ضمن منهج خلاف الأصل ابتداء، فيه نظر، لأغا تققق مبدأ التضامن الاجتماعي، فهي مندرجة فيه، وهذا أصل من أصول الشريعة ومقصد من مقاصدها، باعتباره من وجوه التعاون على البر الذي دعا إليه الشارع الحكيم في محكم تنزيله بصريح العبارة في قوله 
تعالى: الشريعة، حتى أنه لا يمكن أن يختلف اثنان في اعتباره مقصدا عاما من المقاصد الشرعية الثابتة المعلومة من الدين بالضرورة. وموارد البر المفضية إلى تحقيق المصالح لا يمكن أن تكون على خلاف الأصل لأها في حد ذاتما أصل. فضلا عن كون إفضائها إلى تلك المصالح على سبيل الدوام الجاري بلا انقطاع، وليس على سبيل الاستثناء الظريف، حتى تلحق حكمها الشرعي بطريق غير طريق الأصل.

ومنتهى القول في هذا المقام أن التضامن والتكافل الاجتماعي أصل في ذاته قائم بنفسه في الشريعة الإسلامية، وكل ما اندرج فيه من الفروع الفقهية هو داخل في ذلك الأصل بالضرورة ولا صلة له بخلاف الأصل. ومن ثم فإن تلك المظاهر وغيرها من مظاهر التضامن الاجتماعي داخلة فيه، ولا مساغ لإلحاقها بدليل الاستحسان ولا غيره من أدلة ومفاهيم خلاف الأصل. وسلوك هذا النهج في تأصيل الفروع قد أورث منذ القديم شبهات علقت باسم الشريعة نفسها ولا يليق انتهاجه بجددا في تأصيل الوقائع المعاصرة، وخاصة ما اتسم منها بالسمة الاجتماعية، نظرا لأهمية ذلك النمط من الوقائع والمعاملات وجلاء صلاحها. 